del passato - passato così appesantito anche da mitologemi romantici e nazionalisti. Vorrei sottolineare che questo tipo di lavori - che nascono lontani dalle scuole storiche bulgare, greche, serbe o macedoni (segnate più dal patriottismo che dal bisogno di creare un sano discorso scientifico) - con il loro approccio obiettivo riescono a scoprire il vero significato di personaggi ed eventi storici, importanti per la storia di diversi popoli balcanici. Ciò avviene in particolar modo quando questi personaggi ed eventi vengono percepiti come parte inseparabile della coscienza storica dei diversi popoli. Più di vent'anni fa il bizantinista serbo, Srđan Pirivatrić, ha pubblicato la monografia Lo stato di Samuele ${ }^{4}$, dove sono state ben dimostrate - sulla base di documenti, materiale archeologico ed epigrafico - le relazio-

4 С. ПиривАтРИћ, Самуилова држава, Београд 1997. Trad. bulg.: С. ПиривАТрич, Самуиловата държава, trans. С. Стоянов, София 2000. ni tra lo zarato di Samuele con le terre allest della Bulgaria, occupate dopo il 971, e in linee generali l'importanza del regno di Samuele per la continuità della tradizione del I Impero Bulgaro, fino al 1018, l'anno della presa del potere da parte del Bisanzio. Sono convinto che la monografia di M.J. Leszka avrà un ruolo simile: priva di pregiudizi, toglie a Simeone Il Grande l'aureola dei mitologemi nazionalistie patriottici, per ridare così, paradossalmente, a questo personaggio la gloria di una delle principali figure della scena politica del sud-est europeo medievale. In questo senso, la traduzione della monografia Simeone Il Grande e il Bisanzio in lingua bulgara sarebbe una grande sfida sia per i bizantinisti polacchi che peri loro colleghi bulgari, e potrebbe essere l'inizio non solo di una maggiore diffusione della medievistica polacca, ma anche di un dialogo tra i rappresentanti di diverse scuole storiche: un augurio che senza dubbio porterebbe molti benefici per la scienza.

Georgi Minczew (Łódź)

\title{
МАРИЯНА ЦИБРАНСКА-КОСТОВА, Сборникът «Различни потреби» на Яков Крайков между Венеция и Балканите през XVI век [Сборник «Раз- личные потребии" Якова Крайкова между Венецией и Балканами в XVI-ом веке], «Валентин Траянов», София 2013, рр. 191.
}

Для письменной культуры южных славян, в том числе для болгар, XVI-ый век рассматривается как своего рода переходный этап, открывающий и предвещающий в определенном смысле так называемый преднациональный (предвозрожденческий) период ${ }^{1}$. Одним из проявлений этой переходности является постепенная замена рукописной традиции старопечатной (впрочем, обе традиции в это время сосуществуют и влияют друг на друга). В связи с этим изучение славянских старопечатных памят-

\footnotetext{
${ }^{1}$ Краткий обзор различных концепций периодизации развития болгарского литературного языка представил недавно в общих чертах Иван Харалампиев, cf. И. ХАРАЛАМПИЕВ, Лекиии по история на българския книжовен език до Възраждането, Велико Търново 2012, р. 16-26.
}

ников представляется необычайно важным элементом описания и осмысления процессов, легших в основу создания славянских письменных культур и их языковых систем поздне- и постсредневекового времени.

Новая книга Марианны ЦибранскойКостовой, историка болгарского языка и письменности, а также ведущей болгарской специалистки в области старославянского книгопечатания, посвящена наиболее редкому изданию первопечатника Якова Крайкова и одному из наиболее уникальных с точки зрения содержания кирилловских палеотипов в мире - миниатюрному сборнику «Различные потребии», изданному в Венеции в 1571-1572 гг. (распространенное в литературе неоригинальное название памятника было предложено исследователями в XIX в. на основе информации из колофона). Сборник принадлежит к оригинально- 
му макрожанру славянского (в особенности венецианского) книгопечатания - так называемым «книжкам/сборникам для путешествующих/путешественников» (серб. «зборник за путнике») или «подорожным книжкам» и, по словам М. Цибранской-Костовой, является его последним с точки зрения типологии примером, если не считать перепечатки 1597 г. (р. 40). В качестве первого сборника такого рода может рассматриваться изданный в Венеции Божидаром Вуковичем, первоначально по всякой вероятности в двух вариантах (сокращенном и расширенном) или в двух частях, Молитвенник-сборник, перепечатываемый в последующие годы XVI-го в. уже как единое издание несколько раз ${ }^{2}$.

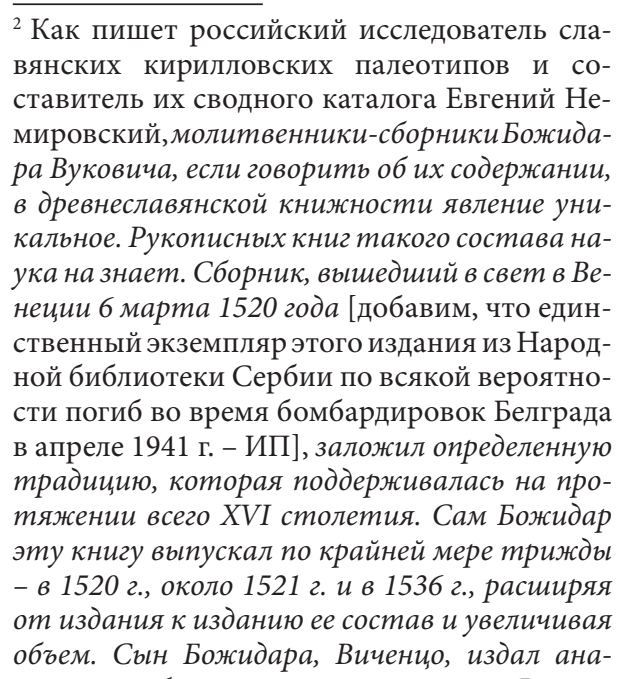
логичные сборники в 1547 и 1560 гг. Яков из Каменной Реки, печатая типографскими материалами Вуковичей, выпустил похожий, но далеко не аналогичный сборник в 1566 году. То же можно сказать о сборнике «Различные потребии», напечатанном в Венеции в 1572 году Яковом Крайковым из Софии. Кроме как в Венеции, аналогичные сборники нигде и никогда не издавались, Е.Л. НЕМИРОвСКИй, Славянские издания кирилловского (иерковнославянского) шрифта 1491-2000. Инвентарь сохранившихся экземпляров и указатель литературь, vol. I: 1491-1550, Москва 2009, p. 109. См. также IDEM, Первые славянские миниатюрные издания, Москва 2000. Стоит отметить, что известная Малая подорож-
Сам сборник «Различные потребии», до сих пор не изданный и даже не дигитализированный, сохранился до наших дней в нескольких полных экземплярах, два из которых находятся в миланской библиотеке «Амброзиана» (Biblioteca Ambrosiana), а один - в университетской библиотеке голландского города Лейдена (Universiteitsbibliotheek Leiden). Представляемая здесь книга является результатом «исследовательских путешествий», как их называет сам автор (р. 6-7), в эти книгохранилища и работы с находящимися там источниками ${ }^{3}$.

Относительно небольшая по объему и формату (что несомненно перекликается с типографическими особенностями самого сборника «Различные потребии»), но в то же время очень насыщенная содержанием публикация состоит из четырех глав, каждую из которых можно рассматривать как своеобразный экскурс, открывающий перед читателем различные аспекты создания памятника и его функционирования в среде южных славян.

ная книжка, выпущенная в 1522 г. в Вильне Франциском Скориной, представляет собой, по мнению некоторых исследователей, несколько иной тип сборника для путешествующих, основанный на восточнославянских образцах, хотя и демонстрирующий определенные параллели с венецианскими изданиями - cf. Z. JAROSZEWICZ-PieresŁAWCEW, Druki cyrylickie $z$ oficyn Wielkiego Księstwa Litewskiego w XVI-XVIII wieku, Olsztyn 2003, p. 27; Franciszek Skoryna z Połocka. Życie i pisma, trans. et ed. M. WalcZaK-MiKoŁajCZaKowa, A. Naumow, Gniezno 2007, p. 27 [= BDE, 3].

${ }^{3}$ Помимо рецензируемой книги, вопросам славянской кирилловской палеотипии посвящены многочисленные статьи М. Цибранской-Костовой, а также кандидатская диссертация и одно отдельно изданное исследование, cf. М. ЦиБРАнСКА, Езикът на печатните книги от XVI в. (по материал на Молитвеника от 1570 г.). Автореферат на дисертация за присъждане на научната степен «Кандидат на филологическите науки", София 1992; ЕАDEM, Етюди върху кирилската палеотипия XV-XVIII век, София 2007. 
Первая глава книги (Въ слдвном' и

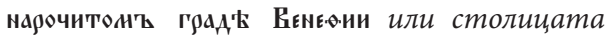
на евпропейското книгопечатане през XVI век [столииа европейского книгопечатания в XVI в.], p. 9-24) не посвящена, как можно было бы заключить из ее заглавия, лишь основным этапам развития книгопечатания (в том числе кирилловского) в Венеции. Вместо сухой фактографии, отказываясь от подробного перечисления функционирующих в Венеции типографий и выпущенных ими книг (хотя такого рода введение и представлялось бы небесполезным), автор увлекательно знакомит читателя с историческим и прежде всего филологическим контекстом создания славянских палеотипов, опираясь на источники, названные в издании анаграфами (болг. анаграфи). Речь идет о дополнительных микротекстах, находящихся вне основного состава данного палеотипа (или шире - данной старопечатной книги) и реализующихся чаще всего в таких «инвариантных жанровых формах» как предисловия и послесловия. Цибранска-Костова подчеркивает, что анаграфические тексты могут рассматриваться и как литературные явления, и как исторические источники: они не только содержат выходные данные конкретного издания, но зачастую открывают перед исследователем географические и биографические детали жизни своих создателей, обосновывают их издательскую программу. Структура этих сжатых текстов необычайно гетерогенна и содержит различные по жанровому происхождению элементы: Печатните предисловия и послесловия обединяват особеностите на различни жанрове, тъй като съдьржат: автобиографичен момент, екзегеза, наратив, публииистичен елемент, наследени трафаретни формули от средновековната книжнина. Това са синкретични текстове, съответстваши на естетиката на средновековната синкретична картина на света, но и пресечна точка на средновековните традиции и новите ренесансови явления (р. 15). В этой же главе автор сосредотачивается на анализе основных употребляемых в анаграфах типографических терминов, таких как ти- пари, фөљни, калапи и др., интерпретируя их возможную этимологию и функции в венецианских изданиях на фоне других (как славянских, так и греческих) балканских и венецианских типографий.

Во второй главе (Язь Їаковь юодонь ш̈ неста нарицанна Gофїа или кой е Яков Крац̆ков? [кто такой Яков Крайков?], р. 25-37) рассматриваются вопросы биографии и происхождения болгарского типографа, причем анализ и предлагаемые выводы также основываются прежде всего на анаграфических текстах из его изданий. Цибранска-Костова вновь поднимает спорный вопрос об идентичности Я. Крайкова и типографа Якова из Каменной реки, также работавшего в Венеции. В этой части книги справедливо замечено, что мнения ученых по данному вопросу довольно четко расходятся: большинство зарубежных исследователей считает, что Яков Крайков и Яков из Каменной реки - это две отдельные личности, в то время как болгарские ученые придерживаются обратного мнения. Автор обращает в этой связи внимание также на недавние работы ряда ученых, в которых приводятся доводы о македонском происхождении Якова из Каменной реки (р. 32-33). Следуя традиции болгарских исследователей и в то же время предлагая ряд новых текстологических аргументов, М. Цибранска-Костова высказывается в поддержку тезиса об идентичности двух Яковов.

Третья, наиболее обширная, глава книгИ (Gьписауь сї̈ нале книге вь ниХь Положихь

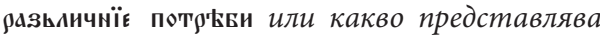
сборникът «Различни потреби»? [что представляет собой сборник «Различные потребии»?], р. 38-135) подробно раскрывает перед читателем состав сборника. После общих генологических и археографических замечаний, в которых - что стоит отметить - указываются недочеты и пропуски некоторых обобщающих археографических работ ${ }^{4}$,

${ }^{4} \mathrm{Ha}$ основе научной литературы и непосредственной работы с источниками М. Цибранска-Костова дополняет и корригирует данные о количестве сохранившихся экземпляров сборника, указанные в отно- 
а также после детального описания находящегося в Лейдене экземпляра сборника, болгарская исследовательница публикует полный список всех содержащихся в сборнике 43 текстов, комментируя оригинальную составительскую стратегию Якова Крайкова на фоне сборников для путешествующих, выпущенных ранее в типографиях Вуковичей и подчеркивая его творческую (а не лишь техническую, как, например, в случае с Виченцо Вуковичем) роль в развитии данногомакрожанра: може да се формулира тезата,

сительно недавно выпущенном каталоге славянских старопечатных изданий: А.A. ГУСЕВА, Издания кирилловского шрифта второй половины XVI века. Сводный каталог, vol. I-II, Москва 2003, р. 442-443. Стоит добавить, что расхождения с данными болгарской исследовательницы повторяются также в новейшем каталоге Е. Немировского (сборник «Различные потребии» описан в нем под номером 138): Е.Л. НЕМИРовСКИЙ, Славянские издания кирилловского (церковнославянского) чирифта 1491-2000. Инвентарь сохранившихся экземпляров и указатель литературь, vol. II,1: 1551-1592, Москва 2011, р. 269-270. В этом - наиболее актуальном, по крайней мере на уровне интенций - издании, Немировский, оставив без внимания ряд итальянских публикаций, фактически повторил археографическую информацию, опубликованную в одном из его более ранних каталогов (сборник «Различные потребии» описан в нем под номером 22): Е.Љ. НЕмИРовскИ, Издана Божидара и вићенияа вуковића, Стеббана Мариновића, Јакова од Камене Реке, Јеролима Загуровића, Јакова Крајкова, Бованиа Антониа Рампацета, Марка и Бартоломеа Ђинамиа (1519-1638), Цетиње 1993 [= Црногорска библиографија, 1494-1994, vol. I,2], p. 183-185. Справедливости ради стоит отметить, что М. Цибранска-Костова один из экземпляров (№ 411 из Архива Сербской академии наук и искусств) называет, как и ряд других ученых, погибшим во время второй мировой войны (р. 42), в то время как имеется его описание (под номером 35), сделанное в середине 80-ых годов XX в., cf. К. МАно-Зиси, Старе ћириличке штампане кюиге у Архиву Српске Академије наука и уметности, АрП 1984/1985, 6/7, р. 309-310. че Яков Крайков е бил добре запознат с постиженията на свочте предходниии, но не е заимствал пряко от тях; че не се е опрял дори на собствените си предходни издания, а се е опитал да предложи нов текстови състав и нови издателски решения; че е искал и е успял да бъде новатор (р. 59). В следующих пунктах третьей главы, на основе анализа календаря, сказания о находящихся в Венеции мощах святых, апокрифов (и других паралитургических текстов), часослова Цибранска-Костова старается подробно и исчерпывающе показать, в чем заключалась эта оригинальность, приводя также множество любопытных текстологических наблюдений. Эта часть исследования, написанная на основе завидной эрудиции автора, может быть интересна палеославистам чрезвычайно многих специальностей и направлений, не только строго филологических.

В завершающей публикацию четвер-

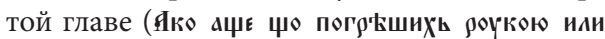
н马ыконь а вїи простете, или каква е общзата езикова характеристика на изданието? [какова обшая языковая характеристика издания?], р. 136-162) читатель может познакомиться с графическим, орфографическим, фонетическим, морфологическим и лексическим анализом языка Якова Крайкова, который дополняет краткий словарь лексики из паралитургической части издания (р. 163-168), содержащий 153 лексемы. Лингвистические наблюдения автора исследования подтверждают, с одной стороны, переходность периода, в который издавался сборник (от старославянских черт к особенностям языковой системы Нового времени), а с другой - ориентировку его создателя, допускавшего появление в тексте сербских, греческих и итальянских языковых черт и заимствований: като самостоятелен издател Яков от София вероятно се е стремял към максимално издателско покритие в геограбския ареал на Балканите. Неговата книга е ориентирана основно към православната славянска диаспора на Венеиия, Далмачия, Дубровник, сърбите и българите на Балканите като обединителен иентьр на православната идея (р. 161). 
Книгу завершают синтетически представленные выводы, важные методологические постановки для дальнейших исследований (р. 169-174) и список использованной литературы. В заключение стоит отметить, что хотя представляемая здесь публикация и является своего рода подведением итогов исследований сборника «Различные потребии» и в целом творчества Якова Крайкова, которые Марианна Цибранска-Костова проводила на протяжении многих лет, ее интерес к этой проблематике не иссяк, о чем свидетельствуют новые статьи, развивающие некоторые тезисы и положения, представленные в книге ${ }^{5}$.

Иван Н. Петров (Лодзъ)

${ }^{5}$ Cf. M. Tsibranska-Kostova, Mount Athos and Venetian Cyrillic printng in the 16th century. The First Bulgarian Printer Jacob Kraykov Interprets the Athonite Legendary History, OCP 80.1, 2014, p. 143-164.

\section{IVAN BILIARSKy, The Tale of the Prophet Isaiah. The Destiny and Meanings of an Apocryphal Text, Leiden-Boston 2013, pp. 310.}

The monograph lives its second life; the first one lasts since 2011, when was edited in Bulgaria and entitled The Tale of Prophet Isaiah and forming a political ideology in Early Medieval Bulgaria $^{1}$. The English edition is not just a translation. As the author emphasizes in the preface, it is significantly enlarged and enriched with ideas, some of which are new, others have been neglected in the Bulgarian version (p. XI).

The idea of Ivan Biliarsky's Tale... is based on commentary to the Medieval ( $11^{\text {th }}$ cent.) text entitled: Tale of the Prophet Isaiah of How an Angel Took Him to the Seventh Heaven, also known as The Bulgarian Apocryphal Chronicle of the $11^{\text {th }}$ century ${ }^{2}$. Let me remind the source text, being the object of the study. The Bulgarian Apocryphal Chronicle is preserved in only one copy, rather late - dating back the $17^{\text {th }}$ cent., the so called Kičevo codex, now in the archives of the State Historical Museum in Moscow (Khludov collection, № 123). For the first time the text was published at the turn of the $19^{\text {th }}$ cent. and ever since is drawing attention of medievists, mostly historians and students of belle-lettres. The text itself originates from the $11^{\text {th }}-13^{\text {th }}$ cent. compila-

\footnotetext{
${ }^{1}$ Ив. Билярски, Сказание на Исайя Пророка и формирането на политическата идеология на ранносредновековна България, София 2011 [Поредица История и книжнина].

${ }^{2}$ Though Biliarsky protests against calling The Tale of the Prophet Isaiah, Bulgarian Apocryphal Chronicle, I do it in order to distinguish the source text and the monograph.
}

tion of another Vision of the Prophet Isaiah, used as the beginning of the tale, with characteristic narration using 1 sing. (I, Prophet Isaiah, beloved among the prophets of our Lord God Jesus Christ, came on God's command to tell you what will happen in the last days of humankind all over the earth. [...] the Heavenly Father [...] sent out me his holy angel and lifted me up from the earth to the heavenly heights..., p. 13). The text is expanded with short narratives concerning history of the Bulgarian state in times of particular rulers, until coming out of certain violent swindlers called Pechenegs, lawless and infidel (p. 21). Ivan Biliarsky presents The Bulgarian apocryphal chronicle as one of most interesting, but - simultaneously - most ambigous and equivocal medieval Bulgarian literary texts. The analysis of the text is additionaly complicated by lack of its ending.

The commentary and interpretation of Ivan Biliarsky are organised in six chapters and three extensive „excurses”, appendixes, being an additional comment to selected questions, only apparently further from the main course of the discourse.

The first chapter, The Text of the Literary Work and Its Manuscript Tradition, is of source character. It contains edition of the old-Bulgarian text and its English translation. The edition is accompanied by reproductions of the manuscript leaves. The context of the literary convoy, in which the Chronicle... is rewritten/copied, seems to be very interesting: texts in memory of Serbian and Bulgarian saints, sermons originat- 